\title{
CAPACITAÇÃO DE PAIS E PROFESSORES DE ESTUDANTES COM TRANSTORNO DE DÉFICIT DE ATENÇÃO E HIPERATIVIDADE/IMPULSIVIDADE: IMPLEMENTAÇÃO EM PARCERIA COLABORATIVA
}

\author{
Camila Rodrigues Costa, Matheus Augusto Mendes Amparo, Manoel Osmar Seabra Junior \\ Universidade Estadual Paulista - UNESP, Departamento de Educação Física, Presidente Prudente, SP. Programa \\ Institucional de Bolsas de Iniciação Científica (PIBIC/CNPq). E-mail: r.camilacosta@gmail.com
}

\begin{abstract}
RESUMO
Este artigo teve como objetivo descrever o processo de desenvolvimento de uma capacitação colaborativa realizada com pais e professores sobre o Transtorno do Déficit de Atenção e Hiperatividade e procedimentos educacionais. Participaram da capacitação, a pesquisadora, uma equipe multidisciplinar composta por, uma fonoaudióloga, uma psicóloga e uma pedagoga, quatro mães, três professoras do ensino comum e uma coordenadora pedagógica da escola. Foram abordados temas como; caracterização e conhecimento do estudante com TDAH e uso de medicamentos; tipos de TDAH e estratégias de ensino e recursos pedagógicos que podem ser utilizados em casa ou na escola com estudantes com TDAH, entre outros. Foram utilizados um gravador para registro de áudio e o registro em diário de campo. Após a análise de conteúdo, foram identificadas cinco categorias que podem subsidiar a elaboração de uma proposta de trabalho colaborativo na escola.
\end{abstract}

Palavras-chave: Capacitação pedagógica. TDAH. Parceria colaborativa. Recursos pedagógicos. Estratégias de Ensino.

\section{TRAINING OF PARENTS AND TEACHERS OF THE STUDENT WITH ATTENTION DEFICIT HYPERACTIVITY DISORDER / IMPULSIVNESS: IMPLEMENTATION IN A COLLABORATIVE PARTNERSHIP}

\begin{abstract}
This article aims to describe the process of development of a collaborative training implemented with parents and teachers about Attention Deficit Hyperactivity Disorder and educational procedures. A researcher, a multidisciplinary team consisting of a speech therapist and a psychologist, four mothers, two regular classroom teachers, and the school's pedagogical coordinator all participated in the training. The topics discussed during the training included characterization and knowledge of the student with ADHD and medication use; types of ADHD, teaching strategies and instructional resources that can be used at home or at school with students with ADHD, among others. The data was collected by recording the audio and keeping field notes. After the content analysis, the researcher identified five categories that can promote the development of a collaborative proposal in school.
\end{abstract}

Keywords: pedagogical training. ADHD. Collaborative partnership. Instructional resources. Teaching Strategies. 


\section{INTRODUÇÃO}

Alguns termos têm sido utilizados, ao longo dos anos, para classificar sujeitos que apresentam um padrão comportamental caracterizado por desatenção e/ou hiperatividade/impulsividade. Atualmente, a denominação utilizada é Transtorno do Déficit de Atenção/Hiperatividade (TDAH), por se tratar de um termo estabelecido por critérios provenientes do Manual Diagnóstico e Estatístico de Transtornos Mentais DSM-V (APA, 2002).

Os prejuízos advindos dos comportamentos da criança com TDAH pode comprometer as relações sociais e afetivas da criança em contextos distintos, como por exemplo, no ambiente escolar e familiar. É importante ressaltar que estas crianças são frequentemente punidas, fato que acarreta agressividade e frustração, comprometendo ainda mais seu comportamento (MATTOS, 2011). Na escola, as características do transtorno ficam evidentes e, em muitos casos, o professor, ao se deparar com a agitação do estudante na sala de aula, não sabe como proceder e sente-se angustiado ou despreparado para atuar.

Estudo realizado por Silva; Cruz; Lima; Asfora, (2010) identificou a partir do relato de professores do ensino comum que eles não se sentem preparados para lidar com o estudante com TDAH, em virtude, da falta de conhecimento sobre as especificidades do transtorno e pela carência de recursos pedagógicos e estratégias de ensino que subsidiem a prática docente.

No ambiente familiar, os comportamentos apresentados pelo estudante em decorrência do transtorno podem alterar a rotina dos membros da família e, em alguns casos, gerar conflitos. Pesquisas realizadas em diversos países com pais de crianças com TDAH demonstram maior prevalência de conflito conjugal e insatisfação, além de alterações nas relações pai-filho com a presença frequente de estilos disciplinares altamente diretivos e hostís ou em alguns casos, excessivamente permissivos (JOHNSTON; MASH, 2001).

Outros estudos, realizados com os responsáveis de crianças com o transtorno indicam que estes apresentam insatisfação com seus papéis parentais e que as mães possuem vulnerabilidade aumentada para doenças como a depressão e há uma maior incidência de consumo de álcool pela família em função do estresse (FARAONE et. al (2003); PODOLSKI ; NIGG, 2001).

A dificuldade dos familiares em lidar com os comportamentos apresentados pela criança com o diagnóstico em geral está relacionada com a falta de informação a respeito do transtorno para uma intervenção eficaz, por meio de estratégias que venham 
ao encontro das necessidades da criança (HECHTMAN, 1996). Os pais e/ou cuidadores, por sua vez, sentem-se desgastados pela necessidade de monitorar frequentemente a criança ou adolescente com TDAH; fator que pode acarretar discussões familiares, acusações, agressões e ressentimentos (MATTOS, 2011).

A partir dos estudos que evidenciaram as dificuldades dos professores e dos pais em como lidar com os estudantes com TDAH em detrimento da falta de conhecimento a respeito das características do transtorno, bem como, pela carência de recursos e estratégias que facilitem a interação e, por conseguinte, a relação estabelecida com o estudante. $\mathrm{O}$ objetivo do presente artigo foi analisar uma capacitação promovida a professores e pais de estudantes com TDAH, realizada de modo colaborativo por meio de uma equipe multidisciplinar.

\section{METODOLOGIA}

O presente estudo atendeu aos requisitos éticos ${ }^{1}$. Trata-se de uma pesquisa qualitativa e descritiva, fundamentada nos pressupostos da pesquisa colaborativa.

A pesquisa colaborativa tem por objetivo criar, nas escolas, uma cultura de análise das práticas realizadas, a fim de possibilitar que professores, auxiliados por

\footnotetext{
${ }^{1} \mathrm{O}$ estudo foi encaminhado e aprovado pelo comitê de ética da faculdade de ciências e tecnologias UNESP campus de Presidente Prudente, seguindo as recomendações vigentes na resolução CNS (Parecer no 388.159).
}

pesquisadores, reflitam a partir da relação de parceria estabelecida e possam transformar suas práticas (IBIAPINA, 2008).

A identificação da necessidade da capacitação teve origem, a partir da aproximação da pesquisadora com as mães de estudantes com TDAH atendidos durante o desenvolvimento de uma pesquisa de iniciação científica PIBIC/CNPq. $\mathrm{Na}$ oportunidade, as mães foram convidadas à participarem das intervenções realizadas com os seus filhos e, por meio, de diálogos a respeito do estudante, percebe-se que as mães não tinham conhecimentos básicos a respeito do transtorno e relataram não saber como proceder em muitos momentos com seus filhos devido a carência de informação e de apoio.

Após essa constatação, a pesquisadora contactou a equipe gestora da escola e propôs uma capacitação por meio de uma parceria colaborativa com profissionais com experiência no trabalho e intervenção com estudantes com o transtorno. Dessa forma, a pesquisadora fez contato com uma equipe multidisciplinar composta por uma psicóloga, uma fonoaudióloga e uma pedagoga que aceitaram o convite para ministrarem uma capacitação para as mães, professores e equipe gestora.

A capacitação ocorreu na escola e foi realizada a partir da parceria colaborativa com uma equipe multidisciplinar. 
Participaram do encontro às quatro mães dos estudantes atendidos, três professoras do ensino comum e a coordenadora pedagógica da escola.

Os temas abordados foram: 1) caracterização do estudante com TDAH; 2) conceitos e importância de conhecer o estudante/filho com TDAH; 3) critérios de diagnóstico e tipos de TDAH; 4) explicação neurológica das características, legislação e uso de medicamentos e 5) estratégias de ensino e recursos pedagógicos que podem ser utilizados em casa ou na escola com estudantes com TDAH.

A coleta de dados ocorreu por meio do uso de um gravador de áudio posicionado em um local estratégico para capturar a fala de todos os participantes. Para complementar essa coleta, também foram elaboradas notas de campo do que foi observado em relação à participação das mães, professoras e gestoras em termos de questionamentos à equipe multidisciplinar e relatos cotidianos das dificuldades enfrentadas ao lidarem com o estudante com transtorno. As notas em diário de campo, nomenclatura utilizada por Vianna (2003), possibilitam o registro diário e minucioso das observações, acontecimentos, manifestação de comportamentos.

Para a análise dos dados, os áudios dos encontros foram transcritos e o material categorizado de acordo com a análise de conteúdo proposta por Bardin (2009). A nota de campo, também, foi submetida à análise de conteúdo e as informações foram classificadas com o objetivo de responder à problemática da pesquisa.

\section{RESULTADOS}

Foram identificadas cinco categorias que podem subsidiar a elaboração de uma proposta de capacitação colaborativa na escola. Categoria 1. Necessidades de informação a respeito do transtorno: o discurso referente à informação sobre o transtorno está presente nas falas das mães e dos professores e foi observada como algo recorrente antes e durante o encontro de capacitação. Dentre os relatos das mães, identificou-se que uma das dificuldades de compreensão sobre o TDAH, diz respeito às terminologias utilizadas pela literatura e outros meios de informação que tratam do transtorno. Além das terminologias, as mães, também, pontuaram que a visita ao médico, em geral, caracteriza-se como um momento em que elas ficam com mais dúvidas, pelo fato do profissional não explicar de forma clara e precisa alguns necessidades do estudante, sobretudo, a respeito do uso do medicamento, frequência e efeitos colaterais. Nos relatos dos professores foi possível identificar que a carência de informação decorre da falta de tempo para estudos sobre o transtorno, devido à carga 
horária excessiva de trabalho, pela demanda e cobrança por resultados.

Categoria 2. Dúvidas frequentes dos pais e professores a respeito do transtorno: as dúvidas frequentes relatadas pelas mães dos alunos são referentes há algumas características do filho, como por exemplo, diferenciar uma conduta inadequada que é realizada de modo proposital, de uma ação realizada devido à falta de autocontrole em decorrência do transtorno. Além disso, outros questionamentos foram realizados como: quais são os efeitos colaterais do medicamento a curto, médio e longo prazo? O transtorno tem relação com o período de gestação, como por exemplo, algum medicamento ingerido ou mesmo o uso de tabaco? O TDAH possui relação genética? Como devem reagir quando o filho possui condutas inadequadas?. Em relação aos professores as dúvidas pontuadas foram como chamar a atenção do aluno para que ele possa realizar a tarefa proposta, visto que, qualquer situação que ocorre na sala de aula ou extra sala de aula faz com que o aluno perca a concentração? Outras indagações foram identificadas como, por exemplo, como conter um aluno que está agitado na sala de aula e o que fazer para que ele não consiga mobilizar toda a turma a terem condutas inadequadas?.

Categoria 3. Necessidades de apoio à prática junto ao estudante/filho com transtorno: os discursos das mães de modo geral, indicaram a necessidade de apoio para lidar com os filhos. Em alguns casos, foram citados até a necessidade de grupos na escola com encontros quinzenais para trocarem informações sobre como uma mãe age, por exemplo, em uma situação onde os familiares estão na mesa para almoçarem e o filho não consegue ficar sentado para comer devido à agitação motora demasiada. No caso dos professores, os relatos indicaram que eles precisam de ajuda de profissionais que os auxiliem no momento de planejamento e elaboração da aula, na adaptação dos conteúdos, bem como, que necessitam do apoio da gestão escolar no sentido de convidarem profissionais experientes na área para tratarem sobre as dificuldades dos professores que geralmente são vivenciadas de modo isolado e se restringe a sala de aula.

\section{Categoria 4. Necessidades de estratégias de} ensino e recursos pedagógicos para lidar com o estudante/filho com transtorno: nos discursos das mães, foi possível identificar a necessidade de ter conhecimento do transtorno, em especial, para saber como lidar com o filho, como estimular ele em casa para que possa aprender na escola. Nas falas dos professores, identificou-se que uma das dificuldades estão em como identificar qual é o melhor recurso pedagógico ou estratégia de ensino para o estudante com TDAH. Em alguns relatos, identificou-se, também, que o 
professor diz que precisa de apoio de outros profissionais, pois durante o planejamento e elaboração das suas aulas consegue perceber as necessidades do estudante, mas não consegue identificar quais recursos e estratégias podem ser utilizados.

Categoria 5. Importância das ações de parceria colaborativa na escola: no relato dos pais, professores e da coordenadora pedagógica identificou-se a importância da parceria colaborativa e de momentos de encontros na escola para discutir a respeito do TDAH, compartilhar estratégias e recursos de sucesso. Assim como, para socializar quais ações não deram certo em casa ou na escola e, principalmente, para estabelecer um "canal" de comunicação mais próximo entre a família e escola, com a colaboração quando possível, de outros profissionais com experiência na área.

\section{DISCUSSÃO}

A participação ativa das mães, professores e gestores da escola por meio dos questionamentos e relatos compartilhados no encontro de capacitação reafirma a necessidade de conhecimento a respeito do transtorno e de partilhar estratégias de ensino e recursos pedagógicos. Além dos benefícios de parcerias colaborativas com o apoio de uma equipe multidisciplinar na escola.
Os resultados dos estudos sobre o cotidiano escolar realizado por Emílio (2004) ressaltam a importância da busca por parcerias da escola com outros profissionaismédicos, psicólogos- que possam auxiliar a família, o aluno e o professor a lidar com as dificuldades cotidianas. Segundo Bauermeister (2009) os pais dos estudantes com TDAH, também, devem estar próximos da gestão escolar, dos professores para acompanhar o desenvolvimento dos filhos e, sobretudo, para comporem uma parceria a fim de discutir e avaliar o processo de ensino e aprendizagem dos seus filhos e para colaborarem com os professores de modo que algumas estratégias de sucesso utilizadas em casa podem ser reproduzidas na escola e - mesmo ocorre quando as estratégias utilizadas pelo professor na escola podem ser eficazes no ambiente familiar.

\section{CONCLUSÃO}

Por todos os fatos mencionados, conclui-se que encontros para capacitação são necessários e que para o sucesso de ações colaborativas na escola, é preciso à participação de diferentes profissionais, dos pais e da equipe gestora.

\section{REFERÊNCIAS}

AMERICAN PSYCHIATRY ASSOCIATION (APA) .Proposed DSM-5 Organizational structure and disorders names, 2011. Disponível em: 
<http://www.dsm5.org/proposedrevision/Pa ges/proposed-dsm5-

organizational-structure-and-disorder-

names.aspx>. Acesso em: 10 jun. 2014.

BARDIN, L. Análise de conteúdo. São Paulo: Edições 70, 2011.

BAUERMEISTER, J. J. Hiperativo, impulsivo, distraído: você me conhece?: guia para pais, professores e profissionais sobre déficit de atenção/José J. Bauermeister: tradução Silvia Massimini Felix. São Paulo: Elevação, 2009.

Emílio, S. A. (2004). O cotidiano escolar pelo avesso: sobre laços, amarras e nós no processo de inclusão. Tese de Doutorado, Faculdade de Psicologia, Universidade de São Paulo, São Paulo, 2004. Disponível em:< http://www.teses.usp.br/teses/disponiveis/4 7/47131/tde-08032006-104424/pt-br.php>. Acesso em 10 ago. 2015.

FARAONE, S. V. ; MONUTEAUX, M. C. ; BIEDERMAN, J. ; COHAN, S. L.; MICK, E. Does parental ADHD bias maternal reports of ADHD symptoms in children? Journal of Consulting \& Clinical Psychology, 71, 168-75, 2003. Disponível em: < http://psycnet.apa.org/journals/ccp/71/1/16 8.pdf>. Acesso em: 15 maio 2014.

HECHTMAN, L. Families of children with attention deficit hyperactivity disorder: a review. Canadian Journal of Psychiatry Revue Canadienne de Psychiatrie 41(6): 350360, 1996.

IBIAPINA, I. M. L. M. Pesquisa colaborativa: investigação, formação e produção de conhecimentos. Brasília: Líder Livro Editora, 2008.

JOHNSTON, C. ; MASH, E. J. Families of children with attention-deficit/hyperactivity disorder: review and recommendations. Clinical Child and Family Psychology Review 4(3): 183-207, 2001. Disponível em: < http://ww1.cpa-
apc.org:8080/Publications/Archives/PDF/199 6/Aug/hechtman.pdf>. Acesso em: 15 maio 2014.

MATTOS, P. No mundo da lua: transtorno do déficit de atenção e hiperatividade. 10 ed. São Paulo - ABDA, 2011.

PODOLSKI, C. L., NIGG, J. T. Parent stress and coping in relation to child DHD severity and associated child disruptive behaviour problems. J Clin Child Psychol, 2001. http://dx.doi.org/10.1207/S15374424JCCP30 $\underline{0407}$

SILVA, E. ; CRUZ, V. V. ; LIMA, W. ; ASFORA, R. TDA/H e prática pedagógica: conhecendo as principais dificuldades a partir de relatos de professores da rede municipal do recife.

2010. Disponível em:< https://www.ufpe.br/ce/images/Graduacao pedagogia/pdf/2010.1/tdah\%20e\%20prtica\% 20pedaggica\%20conhecendo\%20as\%20princi pais\%20dificulda.pdf>. Acesso em: 20 julh. 2015

VIANNA, H. M. Pesquisa em educação: a observação. Brasília: Plano Editora, 2003. 